\title{
Psychiatric disorders in female psychosexual disorders-a nationwide, cohort study in Taiwan
}

\section{Psychiatric disorders and female psychosexual disorders}

\author{
lau-Jin Lin ${ }^{1}$, Nian-Sheng Tzeng ${ }^{2,3}$, Chi-Hsiang Chung ${ }^{4,5,6}$ and Wu-Chien Chien ${ }^{1,4,5,6^{*}}$ (D)
}

\begin{abstract}
We aimed to investigate whether females with psychosexual disorders were associated with the risk of affective and other psychiatric disorders. A total of 2240 enrolled individuals, with 560 patients with psychosexual disorders and 1680 subjects without psychosexual disorders (1:3) matched for age and index year, from the Longitudinal Health Insurance Database, retrieved from the National Health Insurance Research Database (NHIRD), between 2000 and 2015 in Taiwan. The multivariate Cox regression model was used to compare the risk of developing psychiatric disorders during the 15 years of follow-up. There were 98 in the cohort with psychosexual disorders (736.07 per 100,000 person-year) and 119 in the non-cohort without psychosexual disorders (736.07 per 100,000 person-year) that developed psychiatric disorders. The multivariate Cox regression model revealed that the adjusted hazard ratio (HR) was 9.848 ( $95 \% \mathrm{Cl}=7.298-13.291, p<0.001)$, after the adjustment of age, monthly income, urbanization level, geographic region, and comorbidities. Female patients with psychosexual disorders were associated with the risk of psychiatric disorders. This finding could be a reminder for clinicians about the mental health problems in patients with psychosexual disorders.
\end{abstract}

Keywords: Psychosexual disorders, Affective disorders, Females, National Health Insurance Research Database, Cohort study

\section{Background}

Psychosexual disorders could be classified into sexual dysfunctions, paraphilias, and gender identity disorders [1, 2], and these psychosexual disorders are regarded as part of the psychiatric disorders [3]. Previous studies have shown that female patients with psychosexual disorders, such as sexual dysfunctions,

\footnotetext{
* Correspondence: chienwu@ndmctsgh.edu.tw

${ }^{1}$ Graduate Institute of Life Sciences, National Defense Medical Center, 9314R, No.161, Section 6, Min-Chuan East Road, Neihu District, Taipei 11490, Taiwan, Republic of China

${ }^{4}$ Department of Medical Research, Tri-Service General Hospital, National Defense Medical Center, 7115R, No.325, Section 2, Cheng-Gung Road, Neihu District, Taipei 11490, Taiwan, Republic of China

Full list of author information is available at the end of the article
}

paraphilias, and gender identity disorders, would suffer from emotional distress, social embarrassment, and even stigmatization $[4,5]$.

Several researchers have shown the neurodevelopmental interlinks between the psychosexual and psychiatric disorders: Sex differences in the microglial function might partially explain the differences observed in susceptibilities and outcomes of the neuropsychiatric disorders in men and women [6]. Rajkumar (2014) pointed out that both gender identity disorders and schizophrenia are associated with altered cerebral sexual dimorphism and changes in cerebral lateralization [7]. Previous studies have also found that endocrine factors are related to female psychosexual disorders. For example, sex

(c) The Author(s). 2021 Open Access This article is licensed under a Creative Commons Attribution 4.0 International License, which permits use, sharing, adaptation, distribution and reproduction in any medium or format, as long as you give appropriate credit to the original author(s) and the source, provide a link to the Creative Commons licence, and indicate if changes were made. The images or other third party material in this article are included in the article's Creative Commons licence, unless indicated otherwise in a credit line to the material. If material is not included in the article's Creative Commons licence and your intended use is not permitted by statutory regulation or exceeds the permitted use, you will need to obtain permission directly from the copyright holder. To view a copy of this licence, visit http://creativecommons.org/licenses/by/4.0/ The Creative Commons Public Domain Dedication waiver (http://creativecommons.org/publicdomain/zero/1.0/) applies to the data made available in this article, unless otherwise stated in a credit line to the data. 
steroids, such as estrogen or progestin, insufficiency may adversely affect central sexual thought processes, and contribute to the female sexual dysfunctions, such as hypoactive sexual desire disorder [8]. Also, gender dysphoria may have several genes involved in the sex hormone-signaling in the brains [9]. Sex hormones such as estrogen have many effects on anxiety and depression [10]. Several studies have found mutual relations between psychiatric comorbidity and psychosexual disorders [11-16]. For the clinicians, it is essential to better understand the mutual relationship between female patients with psychosexual disorders and their psychiatric morbidity. And these psychiatric disorders might well contribute to the distress, disability, or an increased risk of suffering death, pain, or disability, and consequent behavioral, psychological, or biological dysfunctions [3, 17]. Therefore, several neurodevelopmental, endocrine and psychological factors could be the linkage between psychosexual and psychiatric disorders.

Previous studies have found that depressive disorders are frequently associated with sexual dysfunction, across all the phases of sexual responses [18], and the attention problems related to anxiety might impair sexual motivation even with adequate stimuli [19]. Besides, sexual dysfunction is frequent in patients with posttraumatic stress disorder [20, 21]. However, some researchers have revealed that no psychiatric comorbidity was found in female patients with gender identity disorder [22, 23]. Furthermore, the relationship between female paraphilia and psychiatric disorders remains unclear, since patients with female paraphilia are rare $[24,25]$. Therefore, depression, anxiety, and trauma-related disorders are associated with sexual dysfunctions, and also with the association between psychiatric disorders and paraphilia and gender identity disorder. Besides, there is a gap in the literature that no previous cohort studies have been conducted to examine the risk of psychiatric disorders in female patients with psychosexual disorders. We hypothesize that these psychosexual disorders are associated with the risk of psychiatric disorders in a long-term follow-up. We, therefore, conduct the present study, using Taiwan's National Health Insurance Research Database (NHIRD), to investigate the association between psychosexual disorders and psychiatric disorders, in a 15-year follow-up.

\section{Methods}

\section{Data sources}

The National Health Insurance (NHI) Program was launched in Taiwan in 1995, and as of June 2009, including contracts with $97 \%$ of the medical providers, with approximately 23 million beneficiaries, or more than 99\% of the entire population [26]. The National Health Insurance Research Database (NHIRD) uses the
International Classification of Diseases, 9th Revision, Clinical Modification (ICD-9-CM) codes to record the diagnoses [27]. The present study has used the NHIRD to identify the inpatients with a discharge diagnosis of psychosexual disorders based on the ICD-9-CM codes, including sexual dysfunctions, paraphilia, and gender identity disorders, during 2000-2015. The paraphilias included the diagnoses as exhibitionism, fetishism, frotteurism, pedophilia, sexual masochism, sexual sadism, transvestic fetishism, voyeurism, other paraphilia, and paraphilia, not otherwise specified [3]. All the ICD-9$\mathrm{CM}$ codes of psychosexual disorders are as listed in Table S1. In this database, all the personal identification data were enciphered, for the protection of the privacy of the patients. The records of ambulatory care visits and inpatient claims periodically were reviewed randomly by the NHI Administration to verify the accuracy of the diagnoses [28]. Several previous studies have documented the details of the program [29-33].

\section{Study design and sampled participants}

Patients with newly diagnosed psychosexual disorders were selected from the 2 million Longitudinal Health Insurance Database (LHID), randomized retrieved from the NHIRD, which covers $99 \%$ of the entire population of Taiwan, between January 1, 2000, and December 31, 2015. The patients with psychosexual disorders before 2000 were excluded. Besides, the patients diagnosed with psychiatric disorders before 2000, or before their first visit for any psychosexual disorder, were also excluded. In Taiwan, the legal age of full civil competency is 20 years of age, according to Taiwan's Civil Code [34], therefore, all patients aged $<20$, were excluded as well. In this study, 560 patients with the psychosexual disorder and 1680 subjects without psychosexual disorders, were 1:3 matched, for age and index-year control, with a statistic power of 0.72 [35], and little power improvement resulted from increasing the number of controls while the ratio beyond 1:3 or 1:4 [36]. Therefore, the present study is a population-based, matched cohort study.

\section{Covariates}

The covariates included age groups (20-49, $\geq 50$ years), geographical area of residence (north, center, south, and east of Taiwan), urbanization level of residence (levels 1 to 4), and monthly income (in New Taiwan Dollars [NT\$]; <18,000, 18,000-34,999, $\geq 35,000)$. The urbanization level of residence was defined according to the population and various indicators of the level of development. Level 1 was defined as a population of $>1$, 250,000 , and a specific designation as political, economic, cultural, and metropolitan development. Level 2 was defined as a population between 500,000 and 1,249, 
999, and as playing an important role in the politics, economy, and culture. Urbanization levels 3 and 4 were defined as a population between 149,999 and 499,999, and $<149,999$, respectively.

\section{Comorbidity}

We assessed the comorbidities by using the Charlson Comorbidity Index (CCI), which categorizes comorbidities using the ICD-9-CM codes, and scores each comorbidity category [37-39]. The CCI is used for comorbidity adjustment as a useful measure and substitutes for the usage of the individual comorbidity variables in health services research [40]. In CCI, the comorbidities include myocardial infarction, congestive heart failure, peripheral vascular disease, cerebrovascular disease, chronic obstructive pulmonary disease, dementia, paralysis, diabetes mellitus, diabetes with sequelae, chronic renal failure, cirrhosis of the liver, moderate-severe liver disease, peptic ulcers, rheumatoid arthritis, and AIDS [41]. The combination of all the scores was regarded as a single comorbidity score. A score of zero indicates that no comorbidities were found, and higher scores indicate higher comorbidity burdens [42].

\section{Outcome measures}

Enrolled individuals in these two cohorts were tracked for 15 years, starting from the index date, to identify those who developed psychiatric disorders, comprising dementia, anxiety disorders, depressive disorders, bipolar disorders, eating disorders, sleep disorders, and psychotic disorders, withdrew from the NHI program, or reached the end of 2015. All the ICD-9-CM codes of psychiatric disorders are as listed in Table S1.

\section{Statistical analysis}

All statistical analyses were performed using the SPSS for Windows, version 22.0 (IBM Corp., Armonk, NY). $X^{2}$ and $t$-tests were used to appraise the distributions of the categorical and continuous variables, respectively. The multivariate regression model was used to determine the risk of psychiatric disorders since death can act as a competing risk factor for psychiatric disorders $[43,44]$. The results were presented as a hazard ratio (HR) with a 95\% confidence interval (CI). Differences in the risk of psychiatric disorders between the study and control groups were estimated using the Kaplan-Meier method with the log-rank test. A 2 -tailed $p$-value $<0.001$ was considered to indicate a statistical significance, to minimize the type I error as possible.

\section{Results}

\section{Sample characteristics}

There was no significant difference between these two cohorts in age, marital status, education, insured monthly premiums, and the CCI scores. The cohort with psychosexual disorders tended to search for medical help in summer, autumn, and winter. Furthermore, the cohort with psychosexual disorders tended to live in the north, and the offshore islands resided more in the region of urbanization level 2 and received their medical treatments in the medical centers (Table 1).

\section{The cumulative incidence of psychiatric disorders}

There were 98 in the cohort with psychosexual disorders and 119 in the comparison cohort that developed psychiatric disorders (3444.66 vs 736.07 per 100,000 person-year). Figure 1 depicts that the difference was statistically significant in the Kaplan-Meier survival analysis (log-rank, $p<0.001$ ).

\section{Changes of psychosexual disorders in the follow-up period, 2000-2015}

Figure 2 reveals that there was no significant difference between the beginning and the end-point of the followup in all these psychosexual disorders, between 2000 and 2015. Besides, the treatment prevalence of the female psychosexual disorders was $0.007 \%$ of the sexual dysfunctions, paraphilias were around $0.004 \%$, and the female-to-male (FTM) gender identity disorder was $0.017 \%$, during the 15 -year follow-up.

\section{HR analysis of psychiatric disorders in patients with psychosexual disorders}

The multivariate Cox regression model showed that the adjusted HR of the psychosexual disorders cohort in the development of psychiatric disorders was 9.848 (95\% $\mathrm{CI}=7.298-13.291, p<0.001)$, after adjustment for age, marital status, education, comorbidity (CCI scores), urbanizations/areas of residence, insurance premiums, seasons of visits, and levels of medical facilities, as compared to the control group (Table 2).

\section{Types of psychiatric disorders in female patients with psychosexual disorders}

Table 3 depicts that the cohort with psychosexual disorders, including sexual dysfunctions, paraphilias, and gender identity disorders, were associated with the risk of psychiatric disorders.

Also, there were no significant differences in the times of the psychiatric visits between the two cohorts, even though the cohort with psychosexual disorders had more psychiatric visits than the comparison cohort (3.82 [standard deviation (SD) \pm 4.06 ] vs 3.15 [SD \pm 3.97$]$ ), without a statistical difference $(p=0.001)$ (Table S2). 
Table 1 Characteristics of study at the baseline

\begin{tabular}{|c|c|c|c|c|c|c|c|}
\hline \multirow{2}{*}{$\begin{array}{l}\text { Psychosexual disorders } \\
\text { Variables }\end{array}$} & \multicolumn{2}{|l|}{ Total } & \multicolumn{2}{|c|}{ With } & \multicolumn{2}{|c|}{ Without } & \multirow[t]{2}{*}{$P$} \\
\hline & $\mathrm{n}$ & $\%$ & $n$ & $\%$ & $\mathrm{n}$ & $\%$ & \\
\hline Total & \multicolumn{2}{|l|}{2240} & 560 & 25.00 & 1680 & 75.00 & \\
\hline Age (years) & \multicolumn{2}{|c|}{$35.08 \pm 12.99$} & \multicolumn{2}{|c|}{$34.70 \pm 11.46$} & \multicolumn{2}{|c|}{$35.21 \pm 13.46$} & 0.421 \\
\hline \multicolumn{7}{|l|}{ Age group (years) } & 0.999 \\
\hline $20-49$ & 2016 & 90.00 & 504 & 90.00 & 1512 & 90.00 & \\
\hline$\geqq 50$ & 224 & 10.00 & 56 & 10.00 & 168 & 10.00 & \\
\hline \multicolumn{7}{|l|}{ Married } & 0.692 \\
\hline Yes & 936 & 41.79 & 230 & 41.07 & 706 & 42.02 & \\
\hline No & 1304 & 58.21 & 330 & 58.93 & 974 & 57.98 & \\
\hline \multicolumn{7}{|l|}{ Education (years) } & 0.823 \\
\hline$<12$ & 568 & 25.36 & 144 & 25.71 & 424 & 25.24 & \\
\hline$\geqq 12$ & 1672 & 74.64 & 416 & 74.29 & 1256 & 74.76 & \\
\hline \multicolumn{7}{|l|}{ Insured premium (NT\$) } & 0.663 \\
\hline$<18,000$ & 1974 & 88.13 & 499 & 89.11 & 1475 & 87.80 & \\
\hline $18,000-34,999$ & 184 & 8.21 & 41 & 7.32 & 143 & 8.51 & \\
\hline$\geqq 35,000$ & 82 & 3.66 & 20 & 3.57 & 62 & 3.69 & \\
\hline CCl_R & \multicolumn{2}{|c|}{$0.39 \pm 1.37$} & \multicolumn{2}{|c|}{$0.30 \pm 0.94$} & \multicolumn{2}{|c|}{$0.42 \pm 1.48$} & 0.081 \\
\hline \multicolumn{7}{|l|}{ Season } & $<0.001$ \\
\hline Spring (March-May) & 581 & 25.94 & 91 & 16.25 & 490 & 29.17 & \\
\hline Summer (June-August) & 602 & 26.88 & 154 & 27.50 & 448 & 26.67 & \\
\hline Autumn (September-November) & 476 & 21.25 & 147 & 26.25 & 329 & 19.58 & \\
\hline Winter (December-Februrary) & 581 & 25.94 & 168 & 30.00 & 413 & 24.58 & \\
\hline \multicolumn{7}{|l|}{ Location } & $<0.001$ \\
\hline Northern Taiwan & 945 & 42.19 & 308 & 55.00 & 637 & 37.92 & \\
\hline Middle Taiwan & 581 & 25.94 & 112 & 20.00 & 469 & 27.92 & \\
\hline Southern Taiwan & 574 & 25.63 & 112 & 20.00 & 462 & 27.50 & \\
\hline Eastern Taiwan & 126 & 5.63 & 21 & 3.75 & 105 & 6.25 & \\
\hline Outlets islands & 14 & 0.63 & 7 & 1.25 & 7 & 0.42 & \\
\hline \multicolumn{7}{|l|}{ Urbanization level } & $<0.001$ \\
\hline 1 (The highest) & 784 & 35.00 & 126 & 22.50 & 658 & 39.17 & \\
\hline 2 & 1029 & 45.94 & 357 & 63.75 & 672 & 40.00 & \\
\hline 3 & 112 & 5.00 & 21 & 3.75 & 91 & 5.42 & \\
\hline 4 (The lowest) & 315 & 14.06 & 56 & 10.00 & 259 & 15.42 & \\
\hline \multicolumn{7}{|l|}{ Level of care } & $<0.001$ \\
\hline Medical center & 798 & 35.63 & 357 & 63.75 & 441 & 26.25 & \\
\hline Regional hospital & 595 & 26.56 & 147 & 26.25 & 448 & 26.67 & \\
\hline Local hospital & 847 & 37.81 & 56 & 10.00 & 791 & 47.08 & \\
\hline
\end{tabular}

$P$ : Chi-square / Fisher exact test on category variables and t-test on continue variables

Without married: un-married, divorce, spouse death, and unknown

Education years < 12: elementary school, junior high school, (vocational) high school, and unknown; Education years $\geqq 12$ : university, college, and graduate $C C I R$ Charlson comorbidity index removed dementia

\section{Discussion}

Association between psychosexual disorders and the risk of psychiatric disorders

The adjusted HR was 9.848 (95\% CI $=7.298-13.291$, $p<0.001)$ in the association between the psychosexual disorders and psychiatric disorders, and the female patients with psychosexual disorders had a 9.8-fold increase in the risk of psychiatric disorders, after the adjustment of age, monthly income, urbanization level, geographic region, and comorbidities. The Kaplan-Meier 


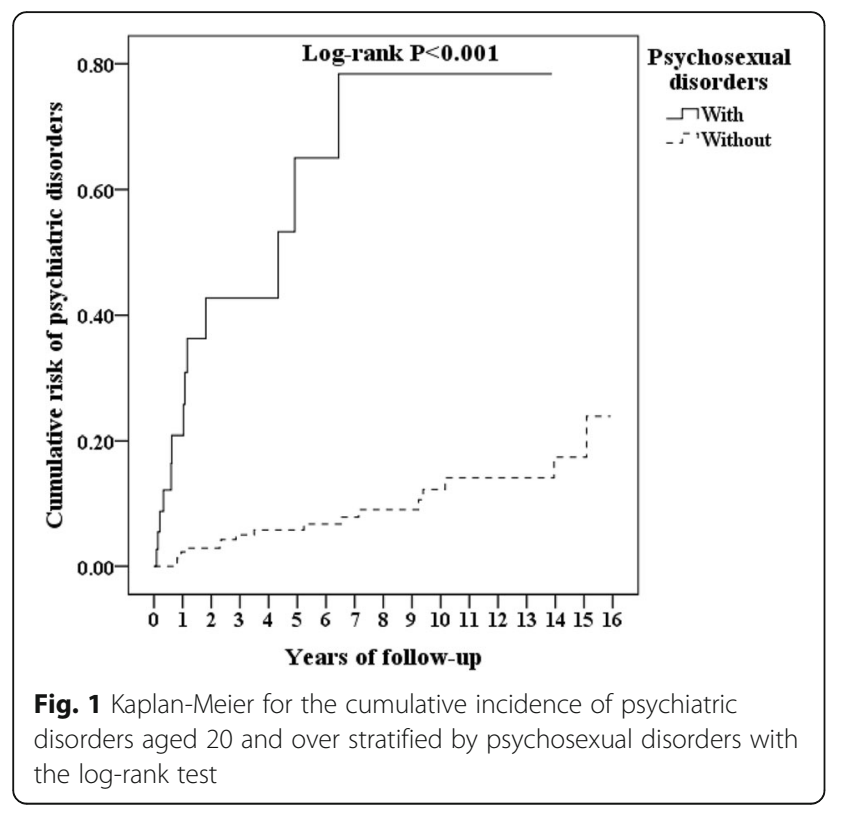

analysis demonstrated that the cohort with psychosexual disorders had a significantly higher 15-year psychiatric disorders cumulative incidence than the comparison cohort. To the best of our knowledge, this is the first study on the topic of an association between female patients with psychosexual disorders and the risk of psychiatric morbidity. This finding could serve as a reminder for the clinicians to pay much more attention to these patients because of the issues about psychiatric disorders.

\section{Comparison of this study to previous literature}

Previous studies have shown the association between psychosexual disorders and psychiatric disorders that included antidepressant-related sexual dysfunctions in patients with depressive or anxiety disorders [16, 4547], female paraphilia focused and the personality disorders on the forensic psychiatric topics [14, 15], and the FTM gender disorders and depression, posttraumatic stress disorder, anxiety disorders and suicides [12, 13, 48]. However, these studies were mostly conducted in cross-section methods, and our study is unique for the retrospective cohort design, from a larger population-based database. Besides, male patients with psychosexual disorders have been associated with an increased risk of anxiety disorders, depressive disorders, bipolar disorders, sleep disorders, and psychotic disorders, respectively [33]. There were several differences in the risk of different psychiatric disorders in these two studies. The underlying reasons for the difference of risk for psychiatric disorders, between female patients with psychosexual disorders, needs further studies.

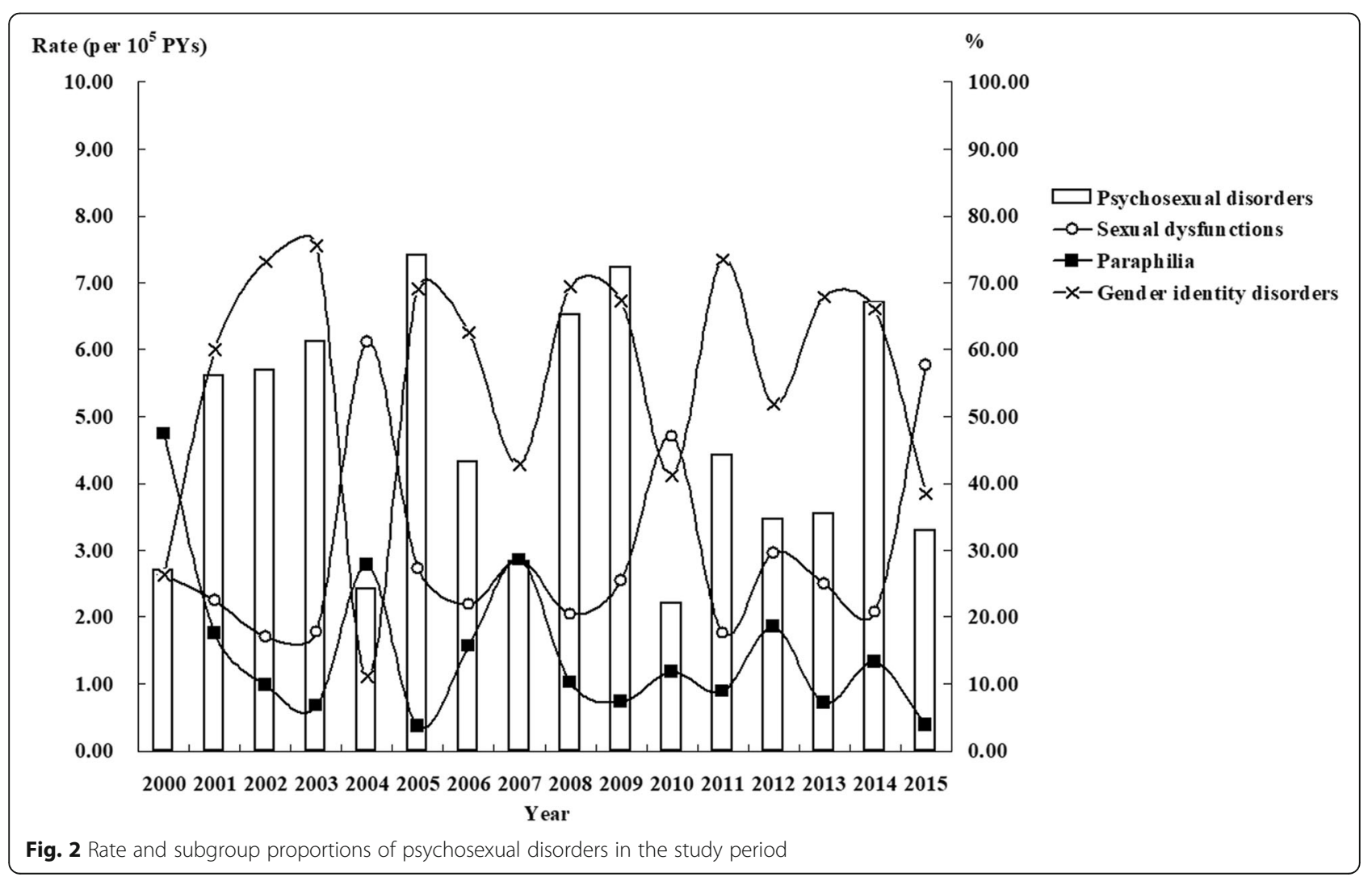


Table 2 Factors of psychiatric disorders stratified by variables listed in the table by using the Cox regression model

\begin{tabular}{|c|c|c|c|c|c|c|c|c|c|c|}
\hline \multirow{2}{*}{$\begin{array}{l}\text { Psychosexual disorders } \\
\text { (With vs. Without) } \\
\text { Stratified }\end{array}$} & \multicolumn{3}{|l|}{ With } & \multicolumn{3}{|c|}{ Without } & \multirow[b]{2}{*}{ Adjusted HR } & \multirow[b]{2}{*}{$95 \% \mathrm{Cl}$} & \multirow[b]{2}{*}{$95 \% \mathrm{Cl}$} & \multirow[b]{2}{*}{$P$} \\
\hline & Event & PYs & $\begin{array}{l}\text { Rate } \\
\text { (per } 10^{5} \text { PYs) }\end{array}$ & Event & PYs & $\begin{array}{l}\text { Rate } \\
\text { (per } 10^{5} \text { PYs) }\end{array}$ & & & & \\
\hline Total & 98 & 2844.99 & 3444.66 & 119 & $16,167.03$ & 736.07 & 9.848 & 7.298 & 13.291 & $<0.001$ \\
\hline \multicolumn{11}{|l|}{ Age group (years) } \\
\hline $20-49$ & 70 & 1823.05 & 3839.71 & 91 & 9797.14 & 928.84 & 8.699 & 6.447 & 11.740 & $<0.001$ \\
\hline$\geqq 50$ & 28 & 1021.93 & 2739.91 & 28 & 6369.89 & 439.57 & 13.117 & 9.720 & 17.703 & $<0.001$ \\
\hline \multicolumn{11}{|l|}{ Married } \\
\hline Yes & 38 & 1400.98 & 2712.38 & 48 & 7754.07 & 619.03 & 9.221 & 6.833 & 12.444 & $<0.001$ \\
\hline No & 60 & 1444.00 & 4155.12 & 71 & 8412.96 & 843.94 & 10.361 & 7.678 & 13.983 & $<0.001$ \\
\hline \multicolumn{11}{|l|}{ Education (years) } \\
\hline$<12$ & 27 & 1034.02 & 2611.17 & 20 & 8026.18 & 249.18 & 22.051 & 16.341 & 29.761 & $<0.001$ \\
\hline$\geqq 12$ & 71 & 1810.97 & 3920.56 & 99 & 8140.85 & 1216.09 & 6.784 & 5.028 & 9.156 & $<0.001$ \\
\hline \multicolumn{11}{|l|}{ Insured premium (NT\$) } \\
\hline$<18,000$ & 67 & 1512.44 & 4429.93 & 73 & 7558.18 & 965.84 & 9.652 & 7.153 & 13.026 & $<0.001$ \\
\hline $18,000-34,999$ & 24 & 851.67 & 2818.01 & 38 & 4311.00 & 881.47 & 6.728 & 4.986 & 9.080 & $<0.001$ \\
\hline$\geqq 35,000$ & 7 & 480.88 & 1455.66 & 8 & 4297.85 & 186.14 & 16.457 & 12.195 & 22.210 & $<0.001$ \\
\hline \multicolumn{11}{|l|}{ Season } \\
\hline Spring & 21 & 535.28 & 3923.14 & 28 & 3746.20 & 747.42 & 11.046 & 8.185 & 14.907 & $<0.001$ \\
\hline Summer & 28 & 1081.07 & 2590.02 & 35 & 4793.88 & 730.10 & 7.465 & 5.532 & 10.075 & $<0.001$ \\
\hline Autumn & 21 & 205.32 & $10,228.13$ & 28 & 3561.62 & 786.16 & 27.378 & 20.289 & 36.950 & $<0.001$ \\
\hline Winter & 28 & 1023.31 & 2736.22 & 28 & 4065.33 & 688.75 & 8.360 & 6.195 & 11.283 & $<0.001$ \\
\hline \multicolumn{11}{|l|}{ Urbanization level } \\
\hline 1 (The highest) & 42 & 1173.26 & 3579.77 & 42 & 5526.97 & 759.91 & 9.913 & 7.346 & 13.379 & $<0.001$ \\
\hline 2 & 35 & 1081.95 & 3234.89 & 42 & 5927.50 & 708.56 & 9.607 & 7.120 & 12.966 & $<0.001$ \\
\hline 3 & 0 & 267.33 & 0.00 & 21 & 1360.70 & 1543.33 & 0.000 & - & - & 0.781 \\
\hline 4 (The lowest) & 21 & 322.44 & 6512.77 & 14 & 3351.86 & 417.68 & 32.813 & 24.316 & 44.285 & $<0.001$ \\
\hline \multicolumn{11}{|l|}{ Level of care } \\
\hline Medical center & 21 & 932.95 & 2250.93 & 21 & 5334.73 & 393.65 & 12.033 & 8.917 & 16.240 & $<0.001$ \\
\hline Regional hospital & 42 & 1076.64 & 3901.02 & 77 & 6635.84 & 1160.37 & 7.075 & 5.243 & 9.548 & $<0.001$ \\
\hline Local hospital & 35 & 835.39 & 4189.64 & 21 & 4196.46 & 500.42 & 17.618 & 13.056 & 23.778 & $<0.001$ \\
\hline
\end{tabular}

PYS Person-years, Adjusted HR Adjusted Hazard ratio: Adjusted for the variables listed in Table 1, CI Confidence interval

\section{Treatment prevalence of psychosexual disorders in this study}

Previous studies revealed that the prevalence of female sexual dysfunctions was $30-60 \%$, in different countries [49-52], but we found that there was $0.007 \%$ of sexual dysfunctions in this sample of 15 year of follow-up. In the present study, there were 70 paraphilia patients from the database, and the treatment prevalence of female paraphilias was around $0.004 \%$ in this LHID. The prevalence of the female paraphilias were $2 \%$ in exhibitionistic behaviors in previous studies [25, 53], $4 \%$ in voyeuristic behaviors $[25,53], 0.4 \%$ in transvestic fetishism [54], and $1 \%$ in sadomasochistic activity [55], from surveys in the population of Sweden [25, 53], and Australia [55]. Previous reports have shown that there were $0.003 \%$ in Belgium, [56], $0.82 \%$ in Japan [57], and 0.023$0.058 \%$ in the United States veteran's populations [12, 58] of FTM gender identity disorder. Furthermore, the present study found that the treatment prevalence of FTM gender identity disorder, was $0.017 \%$, in the duration of the 15 years of follow-up. The discrepancy of the prevalence might be the difference of studies from a claims database or the survey. Cultural differences might also contribute to this difference: previous studies have shown that females have more difficulties in their help-seeking for sex-related problems in Asian countries [59, 60]. However, the 
Table 3 Factors of psychiatric disorders stratified by psychosexual disorders subgroup by using Cox regression mode

\begin{tabular}{lllll}
\hline Psychosexual disorders & Adjusted HR & $\mathbf{9 5 \% ~ C l}$ & $\mathbf{9 5 \%} \mathbf{C l}$ & \multicolumn{1}{c}{$<$} \\
\hline Overall $(\boldsymbol{N}=\mathbf{9 8})$ & 9.848 & 7.298 & 13.291 & 8.757 \\
Sexual dysfunctions $(\boldsymbol{N}=\mathbf{4 2})$ & 6.488 & 4.808 & 45.031 & $<0.001$ \\
Paraphilias $(\boldsymbol{N}=\mathbf{2 1})$ & 33.366 & 24.726 & 16.581 & $<0.001$ \\
Gender identity disorders $(\boldsymbol{N}=\mathbf{3 5})$ & 12.286 & 9.105 & 0.001 \\
\hline
\end{tabular}

PYs Person-years, Adjusted HR Adjusted Hazard ratio: Adjusted for the variables listed in Table 1, Cl Confidence interval

present study is the first one for females with psychosexual disorders and the risk of psychiatric disorders in an Asian country.

Possible mechanisms for the increased risk of psychiatric disorders in patients with psychosexual disorders

In the present study, female patients with sexual dysfunctions were associated with psychiatric disorders. There are several neurodevelopmental, endocrine, and psychological factors related to the linkage between these two groups of disorders. The stress from the suffering of sexual dysfunction [61, 62], paraphilias $[63,64]$, and gender identity disorders [65-67], might well contribute to the association between these psychosexual disorders and the risk of psychiatric disorders, such as anxiety, depressive, or sleep disorders. One study has found that hyperprolactinemia seems to play a role in the pathogenesis of hypoactive sexual desire disorder, one of the female sexual dysfunctions [68], and hyperprolactinemia might induced psychiatric disorders, such as depression and anxiety [69-72].

Evidence suggests that female and male brains are different in the mean volumes of the hippocampus, amygdala, and thalamus [73], the concentration of estrogen or androgen receptors [74], and the total brain, cerebrum, and cerebellum volumes [75]. Thus, the difference in the brain anatomy and neuronal signaling pathways are more closely aligned with a person's perceived gender identity, and individuals with discordant gonadal and brain developments might experience psychological challenges for the generalized dissatisfaction with their biological sex [76]. Besides, paraphilias and depression might share a common dysregulation of this monoaminergic pathway in these patients [11, 77].

Psychological, social, and cultural factors might also contribute to both psychosexual disorders and psychiatric disorders. Previous studies have shown that patients with paraphilias might suffer emotional distress, social embarrassment [4], and stigma [5]. For example, a study from Turkey has found that patients with vaginismus have higher levels of depression and anxiety [78]. Phobic defense mechanisms [79], the rejection of the female role, and religious orthodoxy which regards sex as dirty or shameful [80] are the psychosocial factors that contribute to vaginismus, depression, and anxiety [78].

\section{Limitations}

The present study has several limitations that warrant consideration. First, similar to previous studies using the NHIRD on psychosexual disorders [32, 81-83], we were unable to evaluate the severity, weakness severity, laboratory parameters, or psychological assessments in the patients with psychosexual disorders, since the data were not recorded in the NHIRD. Second, the genetic, psychosocial, and environmental factors, were not included in the dataset. Third, even though we have excluded the patients diagnosed with psychiatric disorders before 2000, or before their first visit for any psychosexual disorders, there is the possibility of the protopathic bias, in which some patients could have been introduced into this study by subjects who have an undiagnosed disease. Fourth, although paraphilias and gender dysphoria are distinct categories, there is some evidence for an overlap between paraphilias and gender dysphoria [84]. The combination of distinct entities, in a single heterogeneous category of psychosexual disorders, is a limitation when discussing the results of the data analysis. Fifth, there is a possibility that the high prevalence of psychiatric disorders, among female patients with psychosexual disorders, is due to the high utilization of psychiatric services. However, as shown in Table S2, there were no significant differences in the times of psychiatric visits between the two cohorts.

\section{Conclusion}

Female patients who suffer from psychosexual disorders have a 9.8-fold increase in the risk of psychiatric disorders, and this finding should serve as a timely reminder for the clinicians to pay much more attention to these patients because of their mental health issues.

\section{Supplementary Information}

The online version contains supplementary material available at https://doi. org/10.1186/s12888-021-03060-1.

Additional file 1: Table S1. ICD-9-CM codes of Psychosexual disorders.

Additional file 2: Table S2. Frequency of psychiatric service. 


\section{Abbreviations}

CCl: Charlson Comorbidity Index; Cl: Confidence interval; FTM: Female-tomale; HR: Hazard ratio; ICD-9-CM: International Classification of Diseases, 9th Revision, Clinical Modification; LHID: Longitudinal Health Insurance Database; NHIRD: National Health Insurance Research Database; NT\$: New Taiwan Dollars

\section{Acknowledgements}

We appreciate the support from the Tri-Service General Hospital Research Foundation and the Medical Affairs Bureau, Ministry of Defense, Taiwan, ROC. We also appreciate the database provided by the Health and Welfare Data Science Center, Ministry of Health and Welfare (HWDC, MOHW).

\section{Authors' contributions}

IJL: Conceptualization, Investigation, Writing-original draft. NST: Data curation, Funding acquisition, Investigation, Methodology, Resources. CHC: Formal analysis, Investigation, Methodology, Software, Visualization. WCC: Conceptualization, Funding acquisition, Methodology, Project administration, Resources, Supervision, Validation, Writing-review \& editing. The author(s) read and approved the final manuscript.

\section{Funding}

This study was supported by The Program for Promoting Teaching Excellence Universities, Ministry of Education (NDMC 104-106: 12-4), the Medical Affairs Bureau, Ministry of Defense (MAB-107-084 and MND-MAB110-087), the Tri-Service General Hospital Foundation (TSGH-C107-004, TSGH-C107-106, TSGH-C108-003, TSGH-C108-151, TSGH-B-109-010, TSGH-E110240, and TSGH-B-110012), and the Taoyuan Armed Forces General Hospital (TYAFGH-A-110020). The sponsors have no role in study design, data collection, and analysis, decision to publish, or preparation of the manuscript. However, all authors declare no financial interests nor conflict of interest or the appearance of a conflict of interest about the work.

\section{Availability of data and materials}

Data are available from the National Health Insurance Research Database (NHIRD) published by the Taiwan National Health Insurance (NHI) Administration. Due to legal restrictions imposed by the government of Taiwan concerning the "Personal Information Protection Act", data cannot be made publicly available. Requests for data can be sent as a formal proposal to the NHIRD (https://dep.mohw.gov.tw/DOS/lp-2506-113.html).

\section{Ethics approval and consent to participate}

This study was conducted according to the Code of Ethics of the World Medical Association (Declaration of Helsinki). The Institutional Review Board of the Tri-Service General Hospital approved this study and waived the need for individual consents since all the identification data were encrypted in the NHIRD (No. 1-106-05-055)

\section{Consent for publication}

Not applicable.

\section{Competing interests}

None

\section{Author details}

${ }^{1}$ Graduate Institute of Life Sciences, National Defense Medical Center, 9314R, No.161, Section 6, Min-Chuan East Road, Neihu District, Taipei 11490, Taiwan, Republic of China. ${ }^{2}$ Department of Psychiatry, School of Medicine, Tri-Service General Hospital, National Defense Medical Center, Taipei, Taiwan, Republic of China. ${ }^{3}$ Student Counseling Center, National Defense Medical Center, Taipei, Taiwan, Republic of China. ${ }^{4}$ Department of Medical Research, Tri-Service General Hospital, National Defense Medical Center, 7115R, No.325, Section 2, Cheng-Gung Road, Neihu District, Taipei 11490, Taiwan, Republic of China. ${ }^{5}$ School of Public Health, National Defense Medical Center, Taipei, Taiwan, Republic of China. ${ }^{6}$ Taiwanese Injury Prevention and Safety Promotion Association, Taipei, Taiwan, Republic of China.
Received: 27 July 2020 Accepted: 18 January 2021

Published online: 28 January 2021

\section{References}

1. Friedman JM, Czekala JE. Psychosexual disorders. In: Morrison RL, Bellack AS, editors. Medical factors and psychological disorders. Boston: Springer; 1987.

2. Crépault C. Classification of psychosexual disorders. Contracept Fertil Sex. 1993;21(2):177-83.

3. American Psychiatric Association. Diagnostic and statistical manual of mental disorders. 4th ed. USA: American Psychiatric Association; 1994.

4. Saleh FM, Berlin FS. Sex hormones, neurotransmitters, and psychopharmacological treatments in men with paraphilic disorders. J Child Sex Abus. 2003;12(3-4):233-53.

5. Jahnke S, Schmidt AF, Geradt M, Hoyer J. Stigma-related stress and its correlates among men with pedophilic sexual interests. Arch Sex Behav. 2015;44(8):2173-87.

6. Hanamsagar R, Bilbo SD. Sex differences in neurodevelopmental and neurodegenerative disorders: focus on microglial function and neuroinflammation during development. J Steroid Biochem Mol Biol. 2016; 160:127-33

7. Rajkumar RP. Gender identity disorder and schizophrenia: neurodevelopmental disorders with common causal mechanisms? Schizophr Res Treatment. 2014;2014:463757

8. Davis SR, Guay AT, Shifren $J L$, Mazer NA. Endocrine aspects of female sexual dysfunction. J Sex Med. 2004;1(1):82-6.

9. Foreman M, Hare L, York K, Balakrishnan K, Sanchez FJ, Harte F, Erasmus J, Vilain E, Harley VR. Genetic link between gender dysphoria and sex hormone signaling. J Clin Endocrinol Metab. 2019;104(2):390-6.

10. Walf AA, Frye CA. A review and update of mechanisms of estrogen in the hippocampus and amygdala for anxiety and depression behavior. Neuropsychopharmacology. 2006;31(6):1097-111.

11. Bradford JM. The paraphilias, obsessive compulsive spectrum disorder, and the treatment of sexually deviant behaviour. Psychiatr Q. 1999;70(3):209-19.

12. Brown $G R$, Jones KT. Mental health and medical health disparities in 5135 transgender veterans receiving healthcare in the veterans health administration: a case-control study. LGBT Health. 2016;3(2):122-31.

13. Dhejne C, Van Vlerken R, Heylens G, Arcelus J. Mental health and gender dysphoria: a review of the literature. Int Rev Psychiatry (Abingdon, England). 2016;28(1):44-57.

14. Segal DL, Gottschling J, Marty M, Meyer WJ, Coolidge FL. Relationships among depressive, passive-aggressive, sadistic and self-defeating personality disorder features with suicidal ideation and reasons for living among older adults. Aging Ment Health. 2015;19(12):1071-7.

15. Turner $D$, Briken $P$. Treatment of paraphilic disorders in sexual offenders or men with a risk of sexual offending with luteinizing hormone-releasing hormone agonists: an updated systematic review. J Sex Med. 2018;15(1):7793.

16. Preeti S, Jayaram SD, Chittaranjan A. Sexual dysfunction in patients with antidepressant-treated anxiety or depressive disorders: a pragmatic multivariable longitudinal study. East Asian Arch Psychiatry. 2018;28(1):9-16.

17. Stein DJ, Phillips KA, Bolton D, Fulford KW, Sadler JZ, Kendler KS. What is a mental/psychiatric disorder? From DSM-IV to DSM-V. Psychol Med. 2010; 40(11):1759-65.

18. Atlantis E, Sullivan T. Bidirectional association between depression and sexual dysfunction: a systematic review and meta-analysis. J Sex Med. 2012; 9(6):1497-507.

19. Bhasin S, Basson R. Sexual dysfunction in men and women. In: Melmed S, Polonsky KS, Larsen PR, Kronenberg HM, editors. Williams textbook of endocrinology. 13th ed. Philadelphia: Elsevier, Inc; 2016. p. 785-830.

20. Yehuda R, Lehrner A, Rosenbaum TY. PTSD and sexual dysfunction in men and women. J Sex Med. 2015;12(5):1107-19.

21. Cosgrove DJ, Gordon Z, Bernie JE, Hami S, Montoya D, Stein MB, Monga M. Sexual dysfunction in combat veterans with post-traumatic stress disorder. Urology. 2002;60(5):881-4.

22. Hoshiai M, Matsumoto $Y$, Sato T, Ohnishi M, Okabe N, Kishimoto Y, Terada S, Kuroda S. Psychiatric comorbidity among patients with gender identity disorder. Psychiatry Clin Neurosci. 2010;64(5):514-9.

23. Simon L, Zsolt U, Fogd D, Czobor P. Dysfunctional core beliefs, perceived parenting behavior and psychopathology in gender identity disorder: a comparison of male-to-female, female-to-male transsexual 
and nontranssexual control subjects. J Behav Ther Exp Psychiatry. 2011; 42(1):38-45.

24. Fedoroff JP, Fishell A, Fedoroff B. A case series of women evaluated for Paraphilic sexual disorders. Can J Hum Sex. 1999;8:127.

25. Dawson SJ, Bannerman BA, Lalumiere ML. Paraphilic interests: an examination of sex differences in a nonclinical sample. Sex Abuse. 2016; 28(1):20-45

26. Ho Chan WS. Taiwan's healthcare report 2010. EPMA J. 2010;1(4):563-85.

27. Chinese Hospital Association. ICD-9-CM English-Chinese Dictionary. Taipei: Chinese Hospital Association Press; 2000.

28. Ministry of Justice. National Health Insurance Reimbursement Regulations. https://law.moj.gov.tw/LawClass/LawAll.aspx?pcode=L0060035. Accessed 31 Dec 2020.

29. Tzeng NS, Chang HA, Chung CH, Lin FH, Yeh CB, Huang SY, Chang CC, Lu RB, Kao YC, Yeh HW, et al. Risk of psychiatric disorders in Guillain-Barre syndrome: a nationwide, population-based, cohort study. J Neurol Sci. 2017; 381:88-94.

30. Chien WC, Chung CH, Lin FH, Chang HA, Kao YC, Tzeng NS. Is weight control surgery associated with increased risk of newly onset psychiatric disorders? A population-based, matched cohort study in Taiwan. J Med Sci. 2017;37(4):137-49.

31. Tzeng NS, Chung CH, Lin FH, Yeh CB, Huang SY, Lu RB, Chang HA, Kao YC, Chiang WS, Chou YC, et al. Headaches and risk of dementia. Am J Med Sci. 2017;353(3):197-206.

32. Yang YJ, Chien WC, Chung CH, Hong KT, Yu YL, Hueng DY, Chen YH, $\mathrm{Ma} \mathrm{H}$, Chang HA, Kao YC, et al. Risk of erectile dysfunction after traumatic brain injury: a nationwide population-based cohort study in Taiwan. Am J Mens Health. 2018. https://doi.org/10.1177/ 1557988317750970

33. Tzeng NS, Yeh HW, Chung CH, Chang HA, Kao YC, Chiang WS, Chien WC. Risk of psychiatric morbidity in psychosexual disorders in male patients: a nationwide, cohort study in Taiwan. Am J Mens Health. 2019;13(2): 1557988319842985.

34. Ministry of Justice. Civil Code. https://law.moj.gov.tw/ENG/LawClass/LawAll. aspx?pcode=B0000001. Accessed 31 Dec 2020.

35. Kang MS, Choi SH, Koh IS. The effect of increasing control-to-case ratio on statistical power in a simulated case-control SNP association study. Genomics Inform. 2009:7(3):148-51.

36. Grimes DA, Schulz KF. Compared to what? Finding controls for case-control studies. Lancet (London, England). 2005;365(9468):1429-33.

37. McGrogan A, Madle GC, Seaman HE, de Vries CS. The epidemiology of Guillain-Barré syndrome worldwide. Neuroepidemiology. 2009;32(2): 150-63.

38. van den Berg B, Walgaard C, Drenthen J, Fokke C, Jacobs BC, van Doorn PA. Guillain-Barre syndrome: pathogenesis, diagnosis, treatment and prognosis. Nat Rev Neurol. 2014;10(8):469-82.

39. Sandoglobulin Guillain-Barre Syndrome Trial Group. Randomised trial of plasma exchange, intravenous immunoglobulin, and combined treatments in Guillain-Barre syndrome. Plasma exchange. Lancet (London, England). 1997:349(9047):225-30.

40. Austin SR, Wong Y-N, Uzzo RG, Beck JR, Egleston BL. Why summary comorbidity measures such as the Charlson comorbidity index and Elixhauser score work. Med Care. 2015;53(9):e65-72.

41. Deyo RA, Cherkin DC, Ciol MA. Adapting a clinical comorbidity index for use with ICD-9-CM administrative databases. J Clin Epidemiol. 1992; 45(6):613-9

42. Needham DM, Scales DC, Laupacis A, Pronovost PJ. A systematic review of the Charlson comorbidity index using Canadian administrative databases: a perspective on risk adjustment in critical care research. J Crit Care. 2005; 20(1):12-9.

43. Marzona I, Baviera M, Vannini T, Tettamanti M, Cortesi L, Riva E, Nobili A, Marcon G, Fortino I, Bortolotti A, et al. Risk of dementia and death in patients with atrial fibrillation: a competing risk analysis of a populationbased cohort. Int J Cardiol. 2016;220:440-4.

44. Blanche P, Proust-Lima C, Loubere L, Berr C, Dartigues JF, Jacqmin-Gadda H. Quantifying and comparing dynamic predictive accuracy of joint models for longitudinal marker and time-to-event in presence of censoring and competing risks. Biometrics. 2015;71(1):102-13.

45. Clayton AH, Gommoll C, Chen D, Nunez R, Mathews M. Sexual dysfunction during treatment of major depressive disorder with vilazodone, citalopram, or placebo: results from a phase IV clinical trial. Int Clin Psychopharmacol. 2015;30(4):216-23.

46. Jacobsen PL, Mahableshwarkar AR, Palo WA, Chen Y, Dragheim M, Clayton $\mathrm{AH}$. Treatment-emergent sexual dysfunction in randomized trials of vortioxetine for major depressive disorder or generalized anxiety disorder: a pooled analysis. CNS Spectr. 2016;21(5):367-78.

47. Olisah VO, Sheikh TL, Abah ER, Mahmud-Ajeigbe AF. Sociodemographic and clinical correlates of sexual dysfunction among psychiatric outpatients receiving common psychotropic medications in a neuropsychiatric hospital in northern Nigeria. Niger J Clin Pract. 2016;19(6):799-806.

48. Ibrahim C, Haddad R, Richa S. Psychiatric comorbidities in transsexualism: study of a Lebanese transgender population. L'Encephale. 2016;42(6):517-22.

49. Nappi RE, Cucinella L, Martella S, Rossi M, Tiranini L, Martini E. Female sexual dysfunction (FSD): prevalence and impact on quality of life (QoL). Maturitas. 2016;94:87-91.

50. Zhang C, Tong J, Zhu L, Zhang L, Xu T, Lang J, Xie Y. A population-based epidemiologic study of female sexual dysfunction risk in mainland China: prevalence and predictors. J Sex Med. 2017;14(11):1348-56.

51. Lou WJ, Chen B, Zhu L, Han SM, Xu T, Lang JH, Zhang L. Prevalence and factors associated with female sexual dysfunction in Beijing, China. Chin Med J. 2017:130(12):1389-94.

52. Singh JC, Tharyan P, Kekre NS, Singh G, Gopalakrishnan G. Prevalence and risk factors for female sexual dysfunction in women attending a medical clinic in South India. J Postgrad Med. 2009;55(2):113-20.

53. Langstrom N, Seto MC. Exhibitionistic and voyeuristic behavior in a Swedish national population survey. Arch Sex Behav. 2006;35(4):427-35.

54. Langstrom N, Zucker KJ. Transvestic fetishism in the general population: prevalence and correlates. J Sex Marital Ther. 2005;31(2):87-95.

55. Richters J, de Visser RO, Rissel CE, Grulich AE, Smith AM. Demographic and psychosocial features of participants in bondage and discipline, "sadomasochism" or dominance and submission (BDSM): data from a national survey. J Sex Med. 2008:5(7):1660-8.

56. De Cuypere G, Van Hemelrijck M, Michel A, Carael B, Heylens G, Rubens R, Hoebeke $\mathrm{P}$, Monstrey $\mathrm{S}$. Prevalence and demography of transsexualism in Belgium. Eur Psychiatry. 2007;22(3):137-41.

57. Baba T, Endo T, Ikeda K, Shimizu A, Honnma H, Ikeda H, Masumori N, Ohmura T, Kiya T, Fujimoto T, et al. Distinctive features of female-to-male transsexualism and prevalence of gender identity disorder in Japan. J Sex Med. 2011;8(6):1686-93.

58. Blosnich JR, Brown GR, Shipherd Phd JC, Kauth M, Piegari RI, Bossarte RM. Prevalence of gender identity disorder and suicide risk among transgender veterans utilizing veterans health administration care. Am J Public Health. 2013;103(10):e27-32

59. Vahdaninia M, Montazeri A, Goshtasebi A. Help-seeking behaviors for female sexual dysfunction: a cross sectional study from Iran. BMC Womens Health. 2009;9:3.

60. Moreira ED Jr, Kim SC, Glasser D, Gingell C. Sexual activity, prevalence of sexual problems, and associated help-seeking patterns in men and women aged 40-80 years in Korea: data from the Global Study of Sexual Attitudes and Behaviors (GSSAB). J Sex Med. 2006;3(2):201-11.

61. Hamilton LD, Meston CM. Chronic stress and sexual function in women. J Sex Med. 2013;10(10):2443-54.

62. Yazdanpanahi Z, Nikkholgh M, Akbarzadeh M, Pourahmad S. Stress, anxiety, depression, and sexual dysfunction among postmenopausal women in Shiraz, Iran, 2015. J Fam Community Med. 2018;25(2):82-7.

63. Bradford JM, Ahmed AG. The natural history of the paraphilias. Psychiatr Clin North Am. 2014;37(2):xi-v.

64. Kuzma JM, Black DW. Epidemiology, prevalence, and natural history of compulsive sexual behavior. Psychiatr Clin North Am. 2008:31(4):603-11.

65. Colizzi M, Costa R, Pace V, Todarello O. Hormonal treatment reduces psychobiological distress in gender identity disorder, independently of the attachment style. J Sex Med. 2013;10(12):3049-58

66. Matsumoto Y, Sato T, Ohnishi M, Kishimoto Y, Terada S, Kuroda S. Stresscoping strategies of patients with gender identity disorder. Psychiatry Clin Neurosci. 2009;63(6):715-20.

67. Wallien MS, van Goozen SH, Cohen-Kettenis PT. Physiological correlates of anxiety in children with gender identity disorder. Eur Child Adolesc Psychiatry. 2007;16(5):309-15.

68. Corona G, Petrone L, Mannucci E, Ricca V, Balercia G, Giommi R, Forti G, Maggi M. The impotent couple: low desire. Int J Androl. 2005; 28(Suppl 2):46-52. 
69. Hinojosa-Amaya JM, Johnson N, González-Torres C, Varlamov EV, Yedinak CG, McCartney S, Fleseriu M. Depression and impulsivity self-assessment tools to identify dopamine agonist side effects in patients with pituitary adenomas. Front Endocrinol (Lausanne). 2020;11:579606.

70. Ioachimescu AG, Fleseriu M, Hoffman AR, Vaughan lii TB, Katznelson L. Psychological effects of dopamine agonist treatment in patients with hyperprolactinemia and prolactin-secreting adenomas. Eur J Endocrinol. 2019;180(1):31-40.

71. Krysiak R, Szkróbka W, Okopień B. The effect of bromocriptine treatment on sexual functioning and depressive symptoms in women with mild hyperprolactinemia. Pharmacol Rep. 2018;70(2):227-32.

72. Liao WT, Bai YM. Major depressive disorder induced by prolactinoma--a case report. Gen Hosp Psychiatry. 2014;36(1):125.e121-2.

73. Ritchie SJ, Cox SR, Shen X, Lombardo MV, Reus LM, Alloza C, Harris MA, Alderson $\mathrm{HL}$, Hunter $\mathrm{S}$, Neilson $\mathrm{E}$, et al. Sex differences in the adult human brain: evidence from 5216 UK biobank participants. Cereb Cortex. 2018; 28(8):2959-75.

74. Halpern D. Sex differences in cognitive abilities. New York: Psychology Press; 2012.

75. Ruigrok AN, Salimi-Khorshidi G, Lai MC, Baron-Cohen S, Lombardo MV, Tait RJ, Suckling J. A meta-analysis of sex differences in human brain structure. Neurosci Biobehav Rev. 2014;39(100):34-50.

76. Boucher FJO, Chinnah TI. Gender dysphoria: a review investigating the relationship between genetic influences and brain development. Adolesc Health Med Ther. 2020;11:89-99.

77. Garcia FD, Thibaut F. Current concepts in the pharmacotherapy of paraphilias. Drugs. 2011;71(6):771-90.

78. Karaguzel E, Arslan F, Tiryaki A, Osmanagaoglu M, Kaygusuz E. Sociodemographic features, depression and anxiety in women with lifelong vaginismus. Anatolian J Psychiatry. 2016;17(6):1.

79. Fugl-Meyer KS, Bohm-Starke N, Damsted Petersen C, Fugl-Meyer A, Parish S, Giraldi A. Standard operating procedures for female genital sexual pain. J Sex Med. 2013;10(1):83-93.

80. Rao TS, Nagaraj AK. Female sexuality. Indian J Psychiatry. 2015;57(Suppl 2): S296-302.

81. Chen KF, Liang SJ, Lin CL, Liao WC, Kao CH. Sleep disorders increase risk of subsequent erectile dysfunction in individuals without sleep apnea: a nationwide population-base cohort study. Sleep Med. 2016; 17:64-8.

82. Hou PH, Mao FC, Chang GR, Huang MW, Wang YT, Huang SS. Newly diagnosed bipolar disorder and the subsequent risk of erectile dysfunction: a nationwide cohort study. J Sex Med. 2018;15(2):183-91.

83. Liu HL, Lee HM, Chung YC. Dyspareunia and its comorbidities among Taiwanese women: analysis of the 2004-2010 nationwide health insurance database. J Sex Med. 2015;12(4):1012-8.

84. Zucker K, Seto M. Gender dysphoria and paraphilic sexual disorders. In: Rutter's child and adolescent psychiatry. 6th ed; 2015. p. 983-98.

\section{Publisher's Note}

Springer Nature remains neutral with regard to jurisdictional claims in published maps and institutional affiliations.

\section{Ready to submit your research? Choose BMC and benefit from}

- fast, convenient online submission

- thorough peer review by experienced researchers in your field

- rapid publication on acceptance

- support for research data, including large and complex data types

- gold Open Access which fosters wider collaboration and increased citations

- maximum visibility for your research: over $100 \mathrm{M}$ website views per year

At $\mathrm{BMC}$, research is always in progress.

Learn more biomedcentral.com/submissions 